\title{
A system dynamics model of split-type Stirling refrigerator
}

\author{
B.J. Huang, Y.P. Yang, F.M. Chen, S.B. Chien* and T.F. Shieh* \\ Department of Mechanical Engineering, National Taiwan University, Taipei 10764 , \\ Taiwan \\ *Chung-Shen Institute of Science and Technology, Lung-Tung, Taiwan
}

Received 3 October 1995; revised 8 January 1996

A non-contact and non-destructive technique was used to measure the displacer motion of a split-type Stirling refrigerator and the results were used to derive a system dynamics model. It is found that the split-type Stirling refrigerator is a third-order dynamic system with a zero. The parameters are shown to vary with the cold-end temperature. (C) 1996 Elsevier Science Limited (C1996 Elsevier Science Limited

Keywords: split-type Stirling refrigerator; dynamics model

\begin{tabular}{|llll|}
\hline \multicolumn{2}{|l|}{ Nomenclature } & $X_{\mathrm{d}}$ & Displacer displacement (mm) \\
& & $X_{\mathrm{p}}$ & Piston displacement (mm) \\
$f$ & Frequency $(\mathrm{Hz})$ & $Z_{1}$ & Zero \\
$G_{\mathrm{dp}}(s)$ & Transfer function & & \\
$K$ & Steady-state gain & Greek letters \\
$\mathrm{P}_{1}$ & Pole & $\xi$ & Damping ratio \\
$P_{\mathrm{ch}}$ & Charge pressure $\left(\mathrm{kg} \mathrm{per} \mathrm{cm} \mathrm{cm}^{2}\right.$ gauge, or MPa) & $\omega$ & Angular frequency $\left(\mathrm{rad} \mathrm{s}^{-1}\right)$ \\
$s$ & Laplace variable, complex & $\omega_{\mathrm{n}}$ & Natural frequency $\left(\mathrm{rad} \mathrm{s}^{-1}\right)$ \\
$T_{\mathrm{L}}$ & Cold-end temperature $(\mathrm{K})$ & &
\end{tabular}

The split-type Stirling refrigerator consists of a piston compressor and a cold finger that are connected by a connecting tube. The cold finger essentially includes a regenerator/displacer component, a gas spring and an expansion space (cold head) as shown in Figure 1. The displacer is driven by the pressure wave of helium gas resulting from the reciprocating motion of the piston. The cooling capacity depends on the amplitude variation and the phase shift of

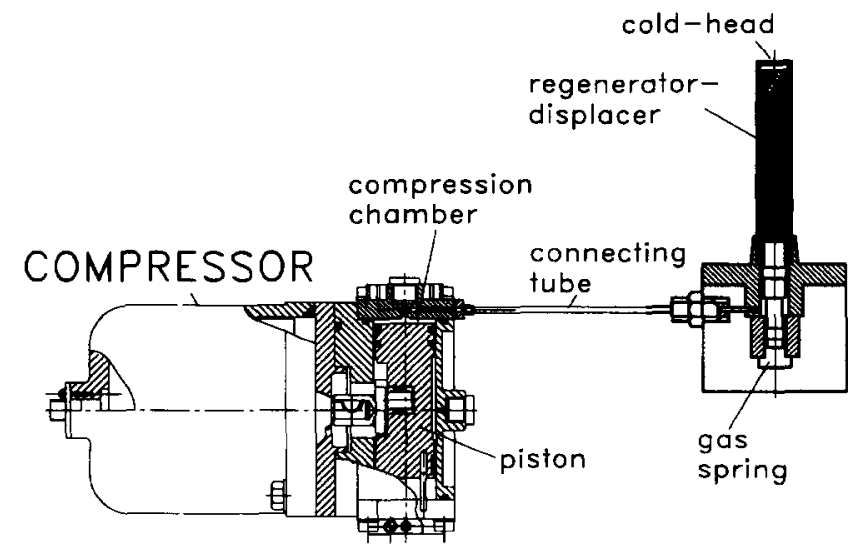

Figure 1 Schematic diagram of split-type Stirling refrigerator the pressure wave and the displacer displacement at the expansion space. The refrigeraor operates at a cyclically steady state due to the oscillating motions of the piston and the displacer that are very close to sinusoidal. The splittype Stirling refrigerator can thus be treated as a dynamic system with the piston displacement $X_{\mathrm{p}}(t)$ as the system input and the displacer displacement $X_{\mathrm{d}}(t)$ and the expansion space pressure $p_{\mathrm{e}}(t)$ as the system outputs ${ }^{1}$.

Understanding the system dynamics model is very important in the control system design of Stirling refrigerators. Some researchers studied the control system design of a Stirling refrigerator experimentally by using a Halleffect sensor ${ }^{2,3}$ or an LVDT (linear variable-differential transformer) sensor ${ }^{4,5}$ installed inside the refrigerator to detect the displacer motion for feedback control or dynamics modelling. A disturbance is thus introduced by the sensor attached to the displacer. The derived system dynamics model of the Stirling refrigerator is therefore inaccurate.

In the present study, we used a new non-contact and nondestructive measuring technique that utilizes an LVDT sensor mounted outside the cold finger to measure the displacer motion ${ }^{6}$. The results were used to derive a system dynamics model of the split-type Stirling refrigerator. 
Table 1 Specifications of an experimental split-type Stirling refrigerator

\begin{tabular}{|c|c|c|c|c|c|}
\hline $\begin{array}{l}1 . \\
2 . \\
3 . \\
4 . \\
5 .\end{array}$ & $\begin{array}{l}\text { Piston stroke } \\
\text { Piston diameter } \\
\text { Displacer diameter } \\
\text { Regenerator diameter } \\
\text { Regenerator length }\end{array}$ & $\begin{array}{l}12 \mathrm{~mm} \\
26 \mathrm{~mm} \\
12.7 \mathrm{~mm} \\
11 \mathrm{~mm} \\
60 \mathrm{~mm}\end{array}$ & $\begin{array}{r}6 . \\
7 . \\
8 . \\
9 . \\
10 .\end{array}$ & $\begin{array}{l}\text { Screen wire disks } \\
\text { Wire mesh } \\
\text { Connecting tube diameter } \\
\text { Connecting tube length } \\
\text { Gas spring volume }\end{array}$ & $\begin{array}{l}700 \\
200 \mathrm{mesh} \\
1.3 \mathrm{~mm} \\
380 \mathrm{~mm} \\
1.0 \mathrm{~cm}^{3}\end{array}$ \\
\hline
\end{tabular}

\section{Experimental set-up}

The LVDT non-contact displacer motion measurement system developed by Yang et al. ${ }^{6}$ was used in the present experiment. A split-type Stirling refrigerator with crankdriven compressor was built for the experiment. The design specifications of the experimental Stirling refrigerator are listed in Table 1. The piston motion was measured by a Keyence LB70 laser measurement system. The laser beam was pointed directly at the bottom end of the piston through a transparent flange which was made of quartz. The displacement signals of the displacer and the piston were measured simultaneously by a Yokogawa YEW3655E multichannel high-speed recorder. A T-type thermocouple was used to measure the cold-end temperature and read by a YEW7563 recorder. All the signals were transmitted to a PC486 through an IEEE488 interface and the data were stored in disk for further analysis.

The $99.999 \%$ pure helium gas was charged to the refrigerator at $6 \mathrm{~kg}$ per $\mathrm{cm}^{2}$ gauge $(0.69 \mathrm{MPa})$ and the frequency was adjusted in the range $18-35 \mathrm{~Hz}$. The cold finger was placed in a vacuum chamber which was evacuated to $10^{-5}$ torr by a diffusion pump so that the heat leak to the cold head is eliminated. The cooling capacity of the refrigerator was determined by measuring the DC current and the voltage across a heating resistance which was glued onto the cold-end surface. The testing conditions are listed in Table 2.

\section{Derivation of system dynamics model}

The system dynamics model of a split-type Stirling refrigerator can be represented by a transfer function which is the ratio of the displacer displacement to the piston displacement:

$G_{\mathrm{dp}}(s)=\frac{X_{\mathrm{d}}(s)}{X_{\mathrm{p}}(s)}$

Since the motion of the displacer and the piston is approximately sinusoidal, the measured displacement signals $X_{\mathrm{d}}(t)$, $X_{\mathrm{p}}(t)$ can be used to directly compute the frequency response of the displacer-to-piston motion:

$G_{\mathrm{dp}}(\mathrm{j} \omega)=\frac{X_{\mathrm{d}}(\mathrm{j} \omega)}{X_{\mathrm{p}}(\mathrm{j} \omega)}$
The conversion of the transfer function in the $s$-plane $G_{\mathrm{dp}}(s)$ from the frequency response function $G_{\mathrm{dp}}(\mathrm{j} \omega)$ can be achieved by simply replacing the angular frequency $\omega$ by $s / j$. This conversion is always assured by the linear system theory if the system is open-loop stable, which is the case for the split-type Stirling refrigerator.

A third-order model including a zero was proposed in the present study to correlate the experimental results:

$G_{\mathrm{dp}}(s)=\frac{K\left[\frac{s}{Z_{1}}-1\right]}{\left(\frac{s}{P_{1}}-1\right)\left[\frac{s^{2}}{\omega_{\mathrm{n}}^{2}}+\frac{2 \xi s}{\omega_{\mathrm{n}}}+1\right]}$

where: $K$ is the steady-state gain; $Z_{1}$ is the zero; $P_{1}$ is the pole; $\omega_{\mathrm{n}}$ is the natural frequency of the displacer; and $\xi$ is the damping ratio. The parameters were determined by fitting the frequency response data to Equation (3) by using a non-linear programming method ${ }^{7}$. It is shown from Figures 2-7 that, the system identification is very good. The model parameters identified are listed in Table 3 .

\section{Discussion and conclusion}

Figures 2 and 3 show the gain and phase at cold-end temperature $213 \mathrm{~K}$. It is shown that the gain $\left|G_{\mathrm{dp}}(\mathrm{j} \omega)\right|$ has a peak value at $30 \mathrm{~Hz}$ with phase lag $90^{\circ}$. For a lower coldend temperature at $193 \mathrm{~K}$, the steady-state gain $K$ increases

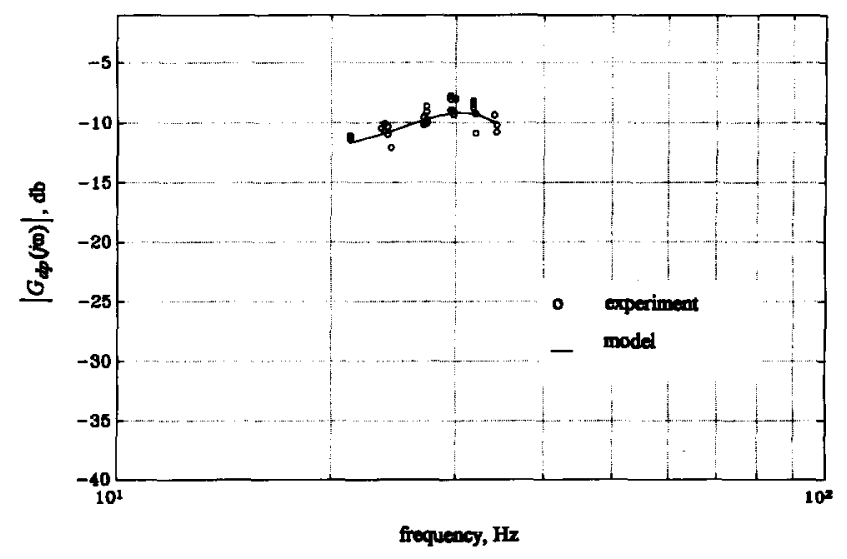

Figure 2 Gain of frequency response at cold-end temperature $T_{L}=213 \mathrm{~K}$

Table 2 Testing conditions

\begin{tabular}{|llllll|}
\hline $\begin{array}{l}\text { Test } \\
\text { No. }\end{array}$ & $\begin{array}{l}\text { Cold-end } \\
\text { temperature, } \\
T_{\mathrm{L}}(\mathrm{K})\end{array}$ & $\begin{array}{l}\text { Charge pressure, } \\
P_{\text {ch }} \\
(\mathrm{kg} \text { per cm }\end{array}$ & $\begin{array}{l}\text { Gas spring } \\
\text { temperature }(\mathrm{K})\end{array}$ & $\begin{array}{l}\text { Compression } \\
\text { space } \\
\text { temperature }(\mathrm{K})\end{array}$ & $\begin{array}{l}\text { Frequency, } \\
f(\mathrm{~Hz})\end{array}$ \\
\hline 1 & 213 & 6 & 320 & 350 & $18.5-34.5$ \\
2 & 193 & 6 & 320 & 350 & $19-34.8$ \\
3 & 173 & 6 & 320 & 350 & $19-32.0$ \\
\hline
\end{tabular}




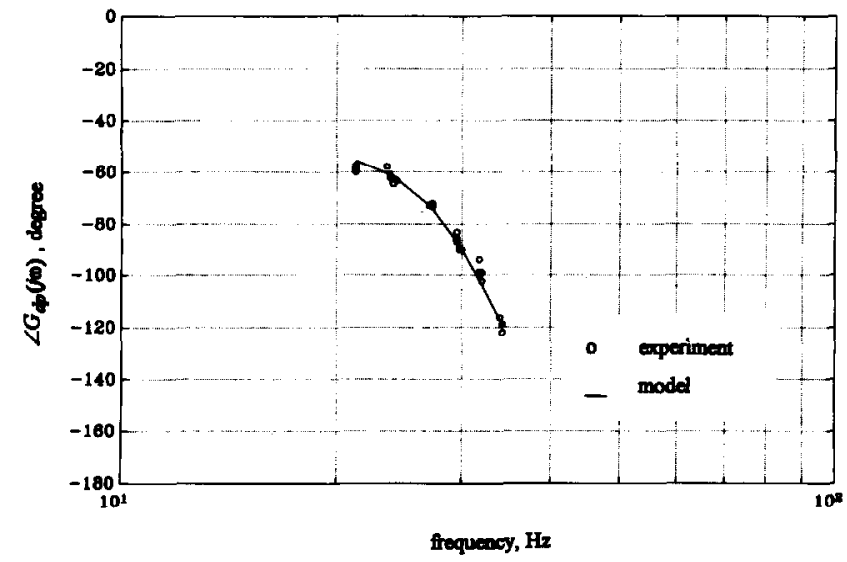

Figure 3 Phase of frequency response at cold-end temperature $T_{L}=213 \mathrm{~K}$

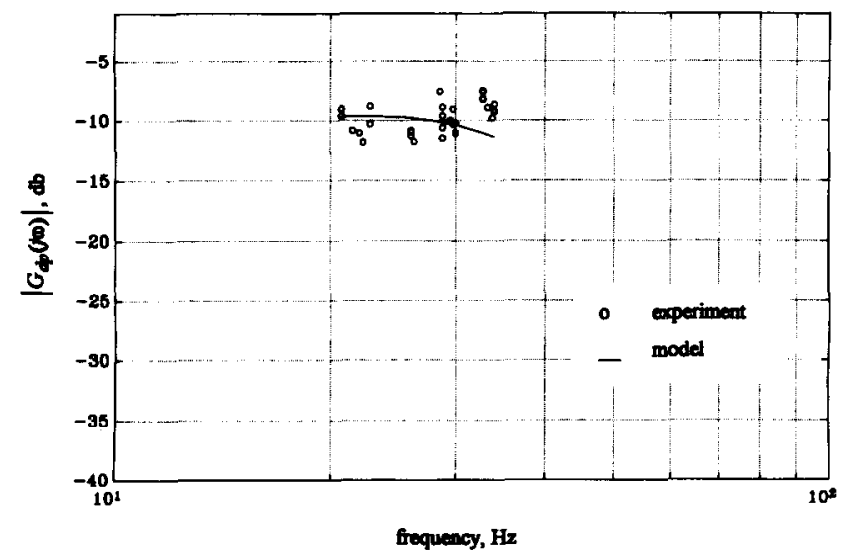

Figure 4 Gain of frequency response at cold-end temperature $T_{L}=193 \mathrm{~K}$

but the peak value of the gain disappears as shown in Figure 4. The phase lag, however, decreases as shown in Figure 5. For the cold-end temperature at $173 \mathrm{~K}$, both the steady-state gain $K$ and the phase lag decrease, as shown in Figures 6 and 7.

The disappearance of the peak value in gain is probably caused by the variation of cylinder (cold-finger) diameter due to the cold-end temperature change. Since the displacer was made from fibre phenolic material and the cold finger from stainless steel $316 \mathrm{~L}$, different thermal shrinkage may occur as the temperature is lowered. A higher cold-end temperature thus results in a larger clearance between the dis-

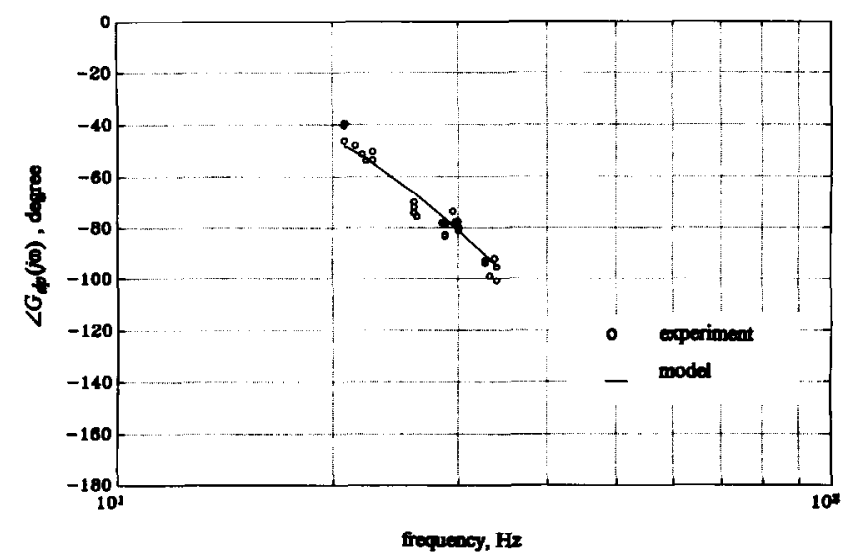

Figure 5 Phase of frequency response at cold-end temperature $T_{L}-193 \mathrm{~K}$

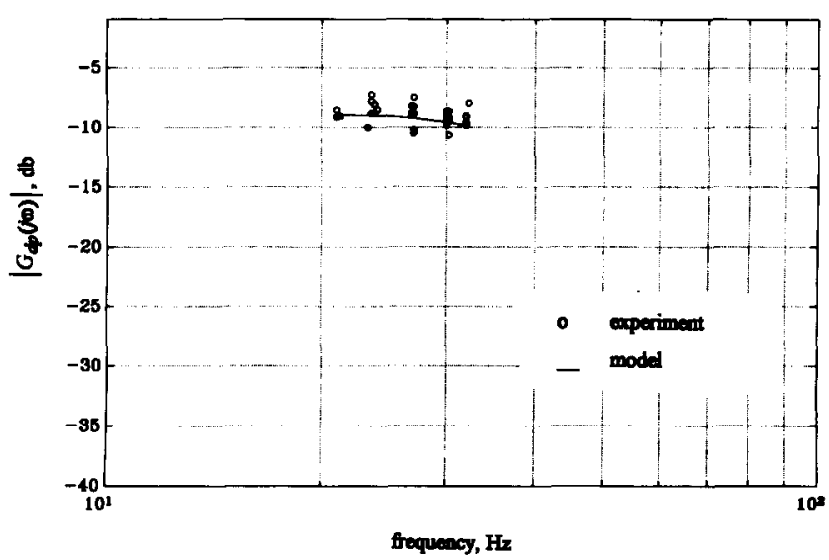

Figure 6 Gain of frequency response at cold-end temperature $T_{\mathrm{L}}=173 \mathrm{~K}$

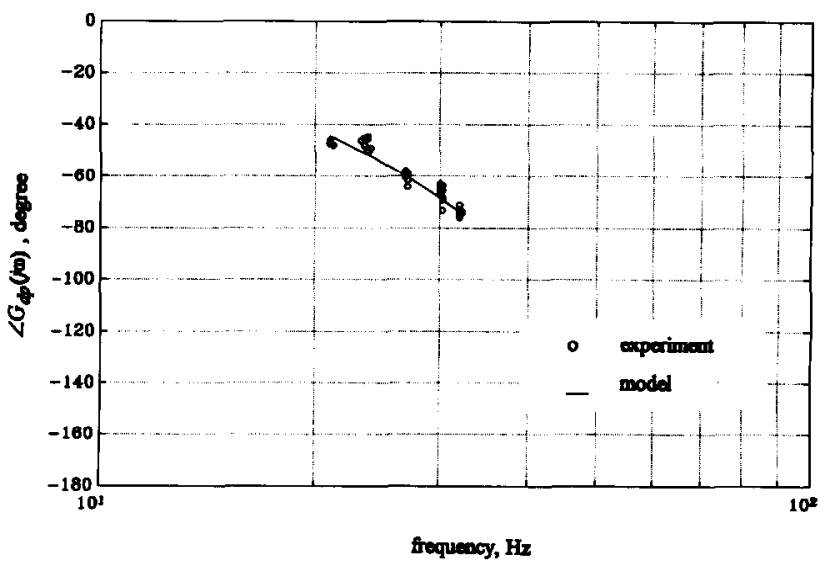

Figure 7 Phase of frequency response at cold-end tempera ture $T_{\mathrm{L}}=173 \mathrm{~K}$

placer and cylinder wall and a small amount of friction. This can be verified by the identified parameters listed in Table 3 in which the damping ratio $\xi$ increases with decreasing cold-end temperature.

The natural frequency $\omega_{n}$, however, remains approximately constant for cold-end temperatures higher than $193 \mathrm{~K}$, as shown in Table 3. The increase in $\omega_{\mathrm{n}}$ at $173 \mathrm{~K}$ is probably due to variation in the gas spring constant caused by gas leakage through the seal.

The dynamics model derived in the present study has one pole and one zero in excess of the second-order model without zeros derived by some other researchers ${ }^{2-5}$. The additional zero $Z_{1}$ obtained in the present study is due to the dynamics behaviour of the regenerator in the process of energy storage/release. It usually has a fast response. The additional pole $P_{1}$ is due to the dynamics behaviour resulting from the fluid transport in the connecting tube In deriving a dynamics model, former researchers ${ }^{2-5}$ only considered the force balance of the displacer and com-

Table 3 System identification results

\begin{tabular}{|llllll|}
\hline $\begin{array}{l}\text { Cold-end } \\
\text { tempera- } \\
\text { ture (K) }\end{array}$ & $K$ & \multicolumn{1}{l}{$\begin{array}{l}\text { Gain } \\
Z_{1}\end{array}$} & $\begin{array}{l}\text { Pole } \\
P_{1}\end{array}$ & $\begin{array}{l}\text { Damping } \\
\text { ratio }\end{array}$ & $\begin{array}{l}\text { Natural } \\
\text { frequency }\end{array}$ \\
\hline 213 & 0.37 & 73.64 & 2.99 & 0.24 & 205.7 \\
193 & 0.52 & 2.66 & 1.49 & 0.51 & 205.1 \\
173 & 0.38 & 1.97 & 1.79 & 0.62 & 240.7 \\
\hline
\end{tabular}


Table 4 Refrigerator performance at $213 \mathrm{~K}$

\begin{tabular}{|llllllll|}
\hline Frequency $(\mathrm{Hz})$ & 19 & 21 & 23.8 & 27 & 29.5 & 31.9 & 34.2 \\
Input power $(\mathrm{W})$ & 32.4 & 36.5 & 37.8 & 40 & 43 & 45 & 47.5 \\
Cooling capacity $(\mathrm{W})$ & 0 & 0.47 & 0.67 & 1.38 & 1.95 & 2.41 & 1.76 \\
Displacer stroke $(\mathrm{mm})$ & 2.96 & 3.33 & 3.49 & 4 & 4.52 & 4.27 & 3.95 \\
Displacer phase lag (degrees) & 53.9 & 58.3 & 62.1 & 72.8 & 87.6 & 98.9 & 119.1 \\
COP & 0 & 0.0129 & 0.0177 & 0.0345 & 0.0453 & 0.0536 & 0.0371 \\
\hline
\end{tabular}

pletely ignored the effects of the regenerator and the connecting tube of the split-type Stirling refrigerator.

It is shown from Table 3 that $Z_{1}$ decreases rapidly with decreasing cold-end temperature as the cold-end temperature starts to decrease from $213 \mathrm{~K}$. For a cold-end temperature below $193 \mathrm{~K}, Z_{1}$ decreases more slowly with cold-end temperature. From linear system theory, a system with a smaller zero will enhance the system response ${ }^{8}$. This indicates that the regenerator response is fast as the cold-end temperature decreases. This coincides with the experience that the regenerator should have a fast response in order to obtain a low cold-end temperature.

The pole $P_{1}$ is shown from Table 3 first to decrease rapidly then increase slowly with cold-end temperature. This indicates that the fluid transport in the connecting tube is faster for lower cold-end temperatures. It was found from the present experiment that, at zero cooling load, the displacer stroke decreases as the cold-end temperature decreases, from $5.4 \mathrm{~mm}$ at $213 \mathrm{~K}$ to $3.2 \mathrm{~mm}$ at $173 \mathrm{~K}$ (both run at $33 \mathrm{~Hz}$ ). The decrease in displacer stroke in turn reduces the gas mass flow rate through the regenerator as well as the connecting tube. The transport speed of gas through the connecting tube is thus reduced as the coldend temperature decreases.

The refrigerator performances at a fixed cold-end temperature of $213 \mathrm{~K}$ were also measured and the results are presented in Table 4. The displacer stroke, cooling capacity and refrigerator COP (coefficient of performance) are all shown to increase with operating frequency, reach a maximum value at $31.9 \mathrm{~Hz}$ then decrease. The input power and the displacer phase lag increase monotonically with frequency. The optimum operating condition for the present refrigerator is at $31.9 \mathrm{~Hz}$ with cooling capacity $2.41 \mathrm{~W}$ and $\mathrm{COP}=0.0536$. This implies that the optimum performance of a split-type Stirling refrigerator depends on the operating conditions such as frequency and cold-end temperature, and the system design such as the regenerator, the displacer, the compressor, the connecting tube, etc. An optimum match should be obtained both in design and operating conditions in order to obtain a better performance.

\section{Acknowledgement}

The present study was supported by the National Science Council, R.O.C. through Grant No. CS84-0210-D-002-027.

\section{References}

1 Huang, B.J. and Lu, C.W. Linear network analysis of split-type Stirling refrigerator Cryogenics (1994) 34 (ICEC Suppl) 207210

2 Xiang Yu, Li Oing and Guo Fangzhong Identification of the negative feedback relationship in split cycle free piston Stirling cryocooler system Cryogenics (1990) 30 (Sept Suppl) 216-220

3 Li Qing, Xiao Jiahua, Guo Fangzhong and Wang Yuelan Dynamic modeling of split cycle free piston Stirling cryocooler Cryogenics (1990) 30 (Sept Suppl) 211-215

4 de Jonge, A.K. A small free-piston Stirling refrigerator 14th IECEC (1979) 1136-1141

5 Stolfi, F. and de Jonge, A.K. Stirling cryogenerators with linear drive Phillips Tech Review (1985) 42 1-10

6 Yang, Y.P., Chien, H.T. and Chen, J.M. Non contact measuremen of displacer motion of a miniature split-Stirling cryocooler Measurement (1995) 14 199-208

7 Seldal, R.C. Transfer-function-parameter estimation from frequency response data-a FORTRAN program, NASA Technical Memorandum NASA TM X-3286 (1975)

8 Nagrath, I.J.and Gopal, M. Control Systems Engineering Wiley Eastern Latd, London (1985) 